\title{
Growing green: the emergent role of non-tilapia attributes in marketing tilapia
}

James A Young, University of Stirling, Scotland j.a.young@stir.ac.uk

David C. Little, University of Stirling_Scotland_dcl1@stir.ac.uk

Andrew Watterson, University of Stirling Scotland aew1@stir.ac.uk

Francis Murray, University of Stirling Scotland f.j.murray@stir.ac.uk

Kathleen Boyd, University of Glasgow Scotland k.boyd@clinmed.gla.ac.uk

William Leschen, University of Stirling Scotland william.leschen@stir.ac.uk

Sarath Kodithuwakku, University of Perideniya Sri Lanka sarath.kodithuwakku2@stir.ac.uk

Professor James A Young

Department of Marketing

University of Stirling

Stirling, FK9 4LA

Scotland, UK

Tel: 01786467383

Fax: 01786464745

Email: j.a.young@stir.ac.uk 


\begin{abstract}
This paper is focussed upon the emergent emphasis of environmentally friendly
\end{abstract} (ENVF) attributes in fish with particular regard to tilapia in the UK. The focus is upon the technical production issues, marketing implications, public health and adoption responses from a 3 years multidisciplinary Research Councils UK project which examined the prospects for UK (agricultural) farmers to diversify into production of warmwater tilapia. The proposed production process and product characteristics abound with green credentials, consistent with emergent market demands. This combination might enable small scale producers to access growing UK niche markets for fresh fish and to compete through upmarket positions with expanding EU tilapia imports. Having ascertained the wider market characteristics, primary research was undertaken through consumer focus groups and indepth interviews with organisational channel members. The results supported the initial premise of niche markets existing for tilapia produced from local, small-scale environmentally-friendly units. Three target groups in the UK were identified: ethnic consumers, green consumers and discrete segments (gastro-pubs and upscale fish restaurants) within foodservice. Having established favourable market prospects the propensity of farmers to diversify into this novel area of activity was explored.

Investigation of farmer entrepreneurship, undertaken in 2006 and 2007, explored perceived challenges in the new aquaculture venture. In-depth face to face and telephone interviews with agricultural farmers identified a number of factors that both encouraged and dissuaded them from diversification into tilapia. Despite the ongoing interests of some, and other emergent adopters, the majority seem disinclined to commercialise their interest. The paper concludes that a more holistic support perspective will be required to promote a more favourable reaction and reviews the prognosis for the success of local fish production. 
Keywords: tilapia, marketing, aquaculture, product diversification.

\section{Introduction}

Sustainable fish production has been pursued globally for decades as wild stocks have declined and aquaculture has emerged as a potential substitute which now accounts for almost $45 \%$ of worldwide fish consumption (FAO, 2009). However, the prospective contributions and impacts of aquaculture in both developed and developing economies are controversial for a variety of reasons (Naylor 2000). These include concerns that industrial fish farming models currently dominating production are both unsustainable and inequitable (Alder et al, 2008) and that they result in public health risks through contaminants in key feed ingredients (Jenkins et al, 2009) . Major global commodity species, notably Atlantic salmon and tropical shrimps depend on fishmeal feeds derived from capture fisheries (Bell and Waagbé, 2008). The negative environmental impacts associated with intensive aquaculture (Diana, 2009) and the potentially adverse public health impacts are likely to impact on market perceptions and positioning. Many of these views remain debateable. In fact, the Monterrey Bay Aquarium’s Seafood Watch lists 11 aquaculture species as Best Choices. These include U.S. farmed catfish and tilapia, Arctic char, barramundi, clams, cobia, mussels, rainbow trout, oysters, bay scallops, and striped bass. However, it may still be argued that aquaculture products are more likely to be accepted where they countermand at least some of the environmental criticisms that have been alleged by some groups. This may suggest that whilst aquaculture will almost certainly play an increasingly important role in aquatic food supplies, there is an urgent need to create, communicate and deliver more positive environmentally-friendly (ENVF) attributes to identified consumer groups (Young et al 1999). This paper reports on this aspect of emergent product attributes in a specific case 
study drawn from a multidisciplinary research project concerned with a radical approach to sustainable food production meeting the evolving environmentally-friendly needs of both consumers and small scale producers in the UK.

The 3-year research project, for Research Councils UK, uniquely incorporated analysis of markets, public health, entrepreneurial decisions in addition to technical aspects of aquaculture systems and fish husbandry (Young et al, 2006). In keeping with the growing emphasis upon more sustainable production systems, the project explored the feasibility of land-based production of the tropical freshwater fish tilapia as an innovative diversification strategy for farmers. The paper initially establishes the wider background context of the project in the context of the evolving sector and the prospects for more ENVF-laden fish products produced in small scale production systems. The technical aspects of such systems are then considered prior to those of the market, based upon secondary data and the qualitative data from a series of focus groups and face to face interviews. The market analysis incorporates in-depth interviews along the supply chain, and with prospective adopters in targeted market segments. The paper concludes with an assessment of the extent to which small scale enterprises may be able to command discrete positions within the market. To appreciate the context and scope of the research some background explanation is provided next.

\section{Background}

Intensification of food production and global markets has encouraged dietary changes in the UK, and elsewhere, over recent decades (Welch and Graham, 1999; Frewer and van Trijp, 2007) with attendant constraints and opportunities for UK farmers. Modern lifestyles and influences from ethnic minorities have impacted upon mainstream food culture, evident in growing cosmopolitan consumption patterns and interest in fresh and novel ingredients. Attitudes to the qualities of food, especially fish, have changed with greater focus upon the 
associated benefits, risks and provenance; an involvement which might be critical to developing marketing opportunities. Relating increasing fish consumption to positive and negative public health impacts has also become commonplace in the media (Burger and Waishwell 2001) although little research has been conducted on the broader implications for public health of UK fish production in terms of wider environmental health impact assessments.

Despite changes in food production, marketing networks and greater diversity of influences on contemporary food culture diet (Welch and Graham, 1999; Anon, 2002), a number of problems remain. It may be argued that new approaches to sustainable food production meeting the needs of producers, consumers and other channel intermediaries are urgently required. Whilst there has been growth in the appropriate variety of food available as one of a number of influences on human health, measurable improvements in public health are naturally lagged and unlikely to appear for several years. Many indicators now reveal there will be major future problems associated with poor eating habits in large sectors of the population. (Rayner \& Scarborough, 2005) In particular, the relative growth of processed 'fast' foods in the diet is believed to be having a deleterious effect, but strategies to inform and provide consumers with healthier and more informed dietary choices appear largely ineffective among the target groups (Glanz, 1999). The potential benefits of increased consumption of particular fish species have failed to reach many target groups. Even where the products have been price competitive such as omega-3 rich pelagic fish species (Gofton \& Marshall, 1992) some prefer to consume the benefits only via more expensive functional products such as fish oil capsules.

Expanding menu choices in the UK’s foodservice and retail niches offer opportunities for suppliers of new products to meet appeals of different socio-cultural groups and with varied willingness and ability to pay. Whilst much of the increased global supply of farmed 
species is likely to continue to be sourced from Asia (Lem \& Emerson, 2008), there are also opportunities within the complex pattern of international trading channels to source shorter marketing chains. A further driver is the structural and spatial distribution of markets: the world's urban population now equals the world's rural population; but urban expansion is set to double within just over 40 years (FAO, 2009). Given the potentially rapid spoilage of fresh fish, closer proximity of points of production and consumption may realise some comparative advantages in freshness and perceived quality in addition to gains in management, transport and handling costs. Furthermore, fish which is produced locally and sustainably forms part of the cachet of green, ethical, health and other attributes.

Conversely, there are many competing alternative food products available and it is a well recognised risk that a wider variety of niche species may crowd a specialised market causing price reductions, even when demand is quite inelastic (Bostock et al 2008). As such specialised low-volume systems inevitably correspond with higher production costs; profit margins could be very sensitive thereby creating a disincentive for farmer to diversify. Notwithstanding the widely accepted positive dietary impacts of eating seafood, increasing evidence suggests some risks to human health through persistent contaminants accumulating in some fish, both wild and farmed ( Wong et al, 2003; Serrano et al 2003). Production of tilapia appears to be a relatively 'green’ alternative capable of satisfying many such ethical and public health concerns. Ecologically, herbivorous tilapias are highly suitable for low impact aquaculture. Not requiring fish or meat-based meals for dietary formulations suggests their culture might be based on organic and non-contaminated ingredients locally sourced, certified and traceable with potential benefits for the local economy. Although imports of tilapia from the tropics are now common, there has been a number start-ups of production systems in the UK and Europe. These range from tens to several thousands of tonnes annual production capacity. These enterprises can produce good quality aquatic foods with low 
environmental impacts and hold scope for integration within conventional terrestrial farms e.g. use of nitrogen rich wastes as fertilisers, recycling of (on-farm) waste heat, specialist marketing through foodservice channels etc. For these reasons, combined with its established favourable flesh characteristics in terms of colour, taste and texture, tilapia was considered to be the most suitable candidate species for diversification.

Nonetheless, a history of start-up failures suggests that significant constraints may exist. Enterprises geared towards large scale buyer demands such as supermarkets have often failed in the past. Several failures have been due to over-reliance on erratic supplies of surplus heat from (third-party) industrial entities. Independently heated recycled aquaculture systems (RAS),are now the norm in Europe and North America. These tend to be technically complex with high investment costs thus discouraging prospective adopters, especially from non-specialist farming communities. However such systems are capable of providing nutritionally-balanced feeds to very high densities of fish, while maintaining water quality and fish welfare through removal of wastes via filtration systems. Questions thus need to be answered about the ability to replicate the advantages of RAS but on a smaller scale more suited to the limited investment capacity of adopters, especially those new to fish farming.

\section{Technical issues}

Farming fish is not a type of diversification that many conventional farmers are familiar with or indeed have considered but our initial assumption was that many of the skills and resources required would be similar; managing feed inputs, managing fluids in the case of dairy production, basic animal husbandry and other suchlike transferable skills. Many farmers have underutilised farm buildings that if insulated could be suitable for warmwater fish production; some have access to on-farm energy sources that have little alternative use such as the surplus heat from milk coolers, methane from livestock slurries. Moreover many farmers were attracted to the project concept through an appreciation of how fish might be a 
valuable and novel product, complementary to their current activities and allowing them to diversify through food production and some of their market channels. Initially it was perceived that a culture system that has been promoted elsewhere but was unproven under commercial UK conditions (Activated Suspension Technology, AST) might be more appropriate for species of fish that are naturally herbivorous and detritivorus such as the tilapias. In contrast conventional RAS was initially viewed as too complex in terms of management and technology. AST is based on the concept of using aerated bacterial floc to convert wastes to natural feed in situ that could theoretically allow internal waste-nutrient recycling and the use of crops grown on farm as the major feedstock. This approach has been described on a small scale and is in commercial use in some tropical tilapia and penaeid shrimp production units (McIntosh, 2000,) Theoretically the application of AST within insulated agricultural buildings offers an alternative approach to tilapia production whilst enhancing its ENVF, ethical and 'local' market attributes. Both approaches have limited, or no, requirements for fish meal and oils in the diets of the herbivorous tilapias and allow retention and theoretically reuse of waste nutrients, either in-situ or locally.

As noted, conventional heated RASs have tended to be technically complex, high cost and thus of limited appeal to non-aquaculturists. Such systems provide nutritionally-balanced processed feeds to very high densities of fish, maintaining water quality and fish welfare through removal of wastes in separate filtration systems. However tilapia naturally feed on the heterotrophic food organisms that thrive on such waste and will grow provided that water quality, especially dissolved oxygen, can be maintained. In turn, as explained above, the need for inclusion of fish and meat meals in feeds can be eliminated. Initially it was hypothesised that lower capital and operating requirements meant AST could produce fish more cost effectively than a conventional RAS, even at lower stocking densities potentially consistent with high welfare standards. Moreover, AST could be more amenable to feeding fish using 
locally produced ingredients and if production was found to be cost effective, then a further incentive would exist for its adoption. Some consideration was given to the scope for seeking organic status, but this was soon dismissed at least in the short run because of the enclosed nature of the culture environment and the tardy development of organic standards for fish.

Key issues to explore under these hypotheses were the relationships between fish density, feeding regime and water quality and their impacts on production efficiency and fish welfare in AST systems. Maintaining warmwater under commercial conditions was not expected to be a major constraint. Preliminary analysis suggested that with modern insulation technologies and internal waste-heat recycling, direct heating costs for both approaches remain below $5 \%$ of total production costs although the costs of pumping (RAS) and aeration (RAS and AST: both key sources of waste heat generation) remain relatively high at around $15-30 \%$ of variable costs, with a contribution inversely proportional to production scale. Nonetheless, the conservative requirements for water in both systems offer wide scope for strategic location, possibly servicing large urban markets or distribution hubs. These issues are linked to both marketing of the product, and consumer and governmental perceptions and understanding of what fish farming might bring in terms of sustainability and public health benefits and /or risks. Indeed they raise the prospect of aquaculture systems being located within urban and other populated environments closer to the centres of demand or at least peri-urban areas with lower land rents, with attendant diminution in the need for food transport and associated costs of handling, storage and spoilage; all factors that would further enhance ENVF attributes.

Despite the theoretical merits of AST particularly with respect to nutrient recycling, a series of technical trials established that it was highly uncompetitive with RAS due to suboptimal growth rates and the risk of stock losses associated with as yet poorly understood bio-floc process instability problems. A comparison of the systems managed on a pilot 
commercial scale concluded that fish welfare and resource use efficiencies were higher for a simple, modular design of RAS. This comparison of technical systems, discussed in more detail elsewhere (Little et al, 2008), is illustrative of some of the technical and financial barriers and knowledge-base uncertainties encountered by prospective adopters, especially those new to fish production. Our findings were in contrast to those published elsewhere (e.g. Avnimelech 1999, Avnimelech et al 1994, Avnimelech 2007) that have raised interest and expectations of AST which we do not believe can be realised in commercial tilapia operations. The conclusion that the novel AST system should be rejected in favour of RAS consumed a lot of project time and resources; and although ultimately not contributing greatly to technical recommendations to farmers, other than what not to do, it provides valuable information for stakeholders within this emerging and important area of aquaculture. This helps build the evidence base for future investors and promoters of ENVF fish production, notably tilapia, and highlights the commercial limitations of what might otherwise appear to be attractive. It is worth noting the technology has had successful commercial application for peneid shrimp culture; species with markedly different feeding and production requirements (Wasielesky et al 2006). In the wider context of emergent aquaculture supplies it contributes to the knowledge base on sustainable aquaculture strategies. A simplified RAS approach was therefore further developed with inputs from our UK-based commercial collaborators with a view to identifying interested adopters in the UK farming industry.

\section{Market considerations}

An integrated approach to identifying market opportunities for various scales of production was pursued throughout the project. Analysis of secondary data found the European market to be relatively small, c.10,000t, compared with the USA's 170,000t and 2.5Mt globally (Josupeit, 2005; 2007; FAO, 2007). The mainstream UK market appeared to 
be a comparatively late and slow adopter of tilapia (Sea Fish Industry Authority, 2008). With only limited market penetration, it was thus decided to use a mixed methods approach (Kent, 2007) involving observational information, consumer focus groups, product placement and in-depth interviews to generate further insights.

Consumer research began at the 2005 Edinburgh Mela (an annual Asian-based multicultural festival) which drew a diverse ethnic and green-leaning group to help formulate the research guide for the focus groups. Apart from the directions of the research guide alternative threads embraced topics raised by respondents to capture their perceived relevancies. The focus groups, held in 2005 and 2006, in five UK cities (Glasgow, Stirling, Edinburgh, Bradford and London) included participants recruited via notices and posters in libraries, community halls, grocery and health food shops and cafes. Recruitment was based upon a self-declared interest in the topic of food and health, plus being a fish consumer. The eleven groups with some 90 consumers reflected a broad spread amongst the standard socioeconomic criteria of age, gender, socioeconomic class and education levels. The focus group discussions were shaped around the issues identified and progressively explored participants' attitudes towards health, food and fish, the perceived health benefits of fish consumption, sustainable food production, organic fish and participants’ awareness, perceptions and purchase habits concerning tilapia. Discussions also touched upon subjects such as fish quality, freshness, packaging and wider concerns with healthy eating, including avoiding or reducing obesity.

The findings from the consumer focus group research clearly identified a strong interest in the pertinent environmental issues surrounding the product. Qualitative data indicated growing awareness and understanding of the underpinning product concepts, although deeper probing revealed some inaccurate information and beliefs, notably one respondent convinced he regularly ate organic mackerel. Participants stated some willingness 
to pay a price premium for the perceived benefits of ENVF attributes, consistent with similar work by Wessells \& Anderson (1995) and Fernandez-Polanco et al (2008). The size of any price premium was found to be variable, with a ceiling comparable to that of organic seafood, typically $+25-30 \%$, but in many case somewhat less than this. In practice clearly, many other factors such as perceived freshness, quality and size, will be critical determinants of any absolute amount paid. Shifts in shopping, notably towards smaller, local outlets and food consumption away from home encouraged individual consumers to be more adventurous and explore alternative markets. Lack of awareness of the emergent options available seemed to present a possible barrier in the short run; however information soon spread through networking and media reporting. Whilst this information flow and exchange may overcome constraints to more localised awareness, ease, and cost, of access to new outlets has to remain competitive and may be more difficult to achieve as production and market areas expand. The discussions confirmed several potential niche markets for the ENVF attributes of such fish produced locally, and germane data were fed back into the cost models for potential adopters.

Given the time taken to undertake the focus groups it was decided not to include exploration of consumers' perceptions of the product at these meetings through sampletasting. In addition to the practicalities of gaining data pre and post-preparation the focus group room setting was considered to be too artificial an environment to gain reliable data. An in-home placement test designed to pick up on standard household fish dish preparation skills and practice, with pre and post consumption interviews, was constrained by available funding and instead it was decided to undertake product placement within apposite segments of the foodservice sector.

\section{Product placement}

Initial small-scale product placement trials were undertaken with two selected foodservice outlets in Devon, a gastro-pub and a Michelin starred restaurant. The location 
enabled the supply of fresh locally produced tilapia from the project's commercial partner within a region where customers had regular access to high quality farmed fish and wild captured supplies from Brixham, a major fishing port in SW England. This provided a competitive test environment and had the additional benefit of availability of commercial fish processing, whose buyers could also be incorporated in other aspects of the product evaluation. The product placement enabled observation of decision making with regards to restaurant food sourcing and menu creation whilst gaining insight into the acceptability of domestically produced tilapia through the reactions of chefs, management and customers.

The participating outlets regularly offered fish options on their menus, sourced local produce and enabled exploration of the proposed target consumers: would they be willing to pay for, try and what did they think of a new or relatively unknown fish product when available in a natural setting? Tilapia was supplied to the establishment free of charge as a whole/round 600g fish then prepared as chefs determined and positioned to diners at a price they felt appropriate. This decision making process was observed and recorded; as were customers in their self-selected out-of-home dining environment after which feedback was sought using an informal and semi-structured interview. This case study approach complemented the focus group work, as discussed above, and the realistic and natural setting of the experiment allowed insights into the actual behaviour of consumers when presented with an unknown and novel, but locally produced, fish product.

In addition to these findings and the focus groups, semi-structured interviews were held with buyers in restaurants, retailers, fish wholesalers and processors which formed a more comprehensive picture of both the potential and limitations of tilapia markets within the UK as discussed below.

\section{Value chain analysis}


In order to supplement the initial product placement study key informant interviews were held along the supply chain centred in the Brixham area. Each was presented with locally produced fresh whole tilapia from the same aforementioned commercial partner and then interviewed on their opinion of the fish, particularly with regard to their views on its prospective position within their markets. Despite the diversity of respondents' channels comments from all quarters were highly favourable. In keeping with the product placement trials, the restaurants in Brixham and Dartmouth, which both have significant high-end foodservice sectors, were left samples for chefs to prepare and place on their menus. This was followed up by face to face and telephone interviews with chefs/ proprietors to discuss their findings which were generally also very positive and confirmed the earlier results. The one notable exception concerned a restaurant run by a TV 'celebrity chef' who accepted the product but refused to comment because the fish was farmed and, for this reason alone, would not be served in his establishment. This reaction was interesting as it highlighted some of the biased and subjective opinions that farmed fish producers might encounter, irrespective of the objective merits of the product in terms of freshness, quality and ENVF attributes.

The combined explorations of consumers and other actors within the marketing chains revealed strong and emergent interests in sourcing, buying and consuming fish products like the tilapia sampled. Limited availability of products fully satisfying desired quality and environmental criteria was reported and the tilapia appeared to be in a favourable position to capitalise upon this situation. Within foodservice chefs consistently reported a willingness to pay ‘reasonable’ premiums so long as quality and other attributes were maintained. The scale of any such price premium was difficult to extract but again views tended to conform within the ceiling found within the focus groups (max 25-30\%), but at apposite wholesale prices. However despite expressed willingness to pay price premiums, normal commercial practice 
might encourage some periodic resistance within market sectors and there will always be pressure to remain competitive with other protein substitutes and establishments.

The production characteristics of tilapia identified were perceived to be valuable, not least because of evident demand for sustainable and eco-friendly food production. Understanding such demand and the opportunities for marketing the product was a key issue and linked to understanding the potential adopters' capacity for both production and marketing. Such a food production system has broader implications than simply the improved livelihoods of mixed farms in the UK. Recent research has identified the nation's poor diet as major contributory factor in health costs and increased fish consumption is being widely advocated as an important remedial measure. Yet this occurs at a time of enhanced consumer concerns with the sustainability of many wild fish stocks and suspicions over conventional aquaculture products on the grounds of their potential impacts on both health and the environment. The project identified various groups of consumers that currently eat fish and might be interested in availability of tilapia produced within the UK as a starting point for understanding the nature of the market(s) for such a 'new' product. Segmentation of these consumers suggested three principal target groups: ethnic consumers, in particular the more affluent with an ability and willingness to pay for product they considered to be superior; green consumers who generally placed high emphasis upon ENVF attributes and discrete segments (notably gastro-pubs and upscale fish restaurants) within foodservice. Research found these groups to present a potential gap in the market that might be satisfied with tilapia from the type of production systems described.

Coincidentally, several new start-up tilapia producers based on a contract farming model appeared in the UK during the project and so generated an opportunity for observation of the viability of a larger-scale, supermarket-driven approach. For a variety of reasons related to both design, operational and marketing inexperience, this route proved particularly 
risky. Its problems did however stimulate the successful initiation of a seed producer with whom there was exchange of both technical information and experience. Having identified seemingly favourable characteristics of the production system and its output, ongoing focus has been placed upon exploration of the interest and capacity among both farmers and other stakeholders in using tilapia as a diversification strategy.

\section{Adopting diversification}

An assessment of farmers' propensity to adopt the proposed ENVF tilapia diversification strategy was begun by gaining understanding of farmers’ current interest in, and practice of, diversification. This was informed by discussions with Government agencies working to promote and support rural diversification. This expertise aided identification of communication channels with target adopters and other institutions that might support this novel activity. Taking on the role of facilitators and providers of neutral, research-based information, the multidisciplinary research team sought to engage their interest and understand their motivations and constraints.

An action research methodology was designed and implemented iteratively and led to dissemination of guidelines through interactive dialogue with potential adopters. Initial dissemination of project objectives was via the project website, followed up by key informant interviews with individuals involved in agriculture and farm diversification in Scotland. From this a database of potential adopters was developed as a sample frame. A series of seventeen face to face interviews was undertaken with a random cross section of farmers located in Central Scotland with, and without, diversification experience; in these entrepreneurship issues were the focus of discussion.

Subsequently, the tilapia diversification concept was launched at livestock auction markets in Central Scotland which typically attracted farmers, as buyers and sellers, from afar and locally. During the markets farmers traditionally spend part of their time networking and 
discussing current farming news which provided an appropriate and receptive environment for demonstration of the project concept. Poster displays, a scaled-production unit and a chef cooking samples of tilapia sent from the commercial partner gave farmers the opportunity to discuss, witness and taste the concept from farm to fork. Most were new to the species and this tangible engagement overcame many potential problems of hypothetical explanations. Informal interviews gave further insights and additions to the database. For those expressing greater interest, follow-up visits were arranged to view a demonstration tilapia RAS at the nearby University hosting the project. This combined approach provided enhanced links with a number of individuals to assess how adoption of tilapia farming might work from both technical and market-focussed perspectives.

Having established clearer insights into the issues perceived to be more critical a larger presentation meeting was held in Perthshire with a cross section of the farming community. Thereafter further dissemination used TV, radio and printed press channels, including UK and Scottish farming publications which generated considerable interest. An information pack, incorporating and integrating findings from all disciplinary perspectives, was generated giving guidelines for starting up small scale tilapia production; this was circulated using the database. Feedback was invited through email or telephone interviews and this iterative process helped inform the decision-making process for potential adopters.

\section{Entrepreneurial responses?}

A total of 273 separate responses, a self-selecting sample from a wide geographical area (95 Scottish, 148 English, 4 Welsh and 26 international) and embracing a diverse structure of farms, were received to the media coverage which expressed interest in the potential for small-scale production, distribution and marketing of tilapia from RAS. Analysis of the responses indicated that both distress and success factors motivated farmers to look outside their current situation for new opportunities; both bring their own challenges with 
respect to converting interest into action. Issues of opportunity and necessity to diversify from conventional agriculture are fundamental in any assessment of motivation to change, especially where it involves movement away from a production based subsidy. Recent growth towards organic and local foods was found to have increased awareness of the market potential and had sown some seeds of more lateral thinking about potential market entry strategies. Concurrent expansion of farmers’ markets, organic box schemes and suchlike seemed to underline more widespread public empathy with food produced locally and ethically and thus a willingness to explore new sources and outlets.

From the trials data, discounted cash flow analysis (incorporating production and marketing costs) demonstrated that breakeven prices (i.e. where IRR $=0$, at a 7 year discount rate of $4 \%$, and assuming an annual production to biomass ratio of 3 based on continuous backstocking of fingerlings) were highly scale sensitive; ranging from of $£ 5.20 / \mathrm{kg}$ to $£ 2.55 / \mathrm{kg}$ for units of $4 \mathrm{t}$ and $30 \mathrm{t}$ annual production capacity respectively. These results suggest a likely cut-off point between 5-10t annual capacity when set against prevailing market prices for competing products. These levels could be reduced through capital grant support schemes though only marginally as operational costs, specifically for food and energy, have a greater influence on profitability. Clearly there were also other concerns not encapsulated in this analysis. After often lengthy consideration of both technical issues and market characteristics the perceived risks outweighed the potential returns for the majority to develop a pilot system. Prospective producers remained sceptical about their ability to service sufficient buyers to be financially viable, especially where seasonal fluctuations in demand was anticipated. The absence of tried and tested market models at appropriate scales and design for new-comers made many unwilling to extend their operational boundaries. Yet clearly this producer-led resistance to expansion of market outlets could present a barrier to consumer access and thus hinder greater acceptance, a classic chicken and egg dilemma. 
Other producers reported the parallels with other types of diversification, especially related to concepts of greener, local food. Paradoxically whilst this reticence exists the potential attractions of early adoption and market entry remain high; but clearly this innovator advantage could diminish as greater numbers enter the market.

The emphasis upon 'small scale' production and niche markets served suggests that communications would best rest upon word of mouth and other below the line activity. The characteristics of the target buyers are such that the success of the venture depends critically upon perceptions of what the product actually delivers, rather than any alternative claims that might be communicated. Foodservice and retail buyers and consumers consistently emphasised product quality to be absolutely vital. Given the structure of the value chain, and its competitors, the freshness and ENVF of the product are the key USPs and the critical point of comparative advantage and potential success. Consistent delivery of these USPs is thus likely to be an ongoing prerequisite for sustainability of the operation.

One evident constraint to adoption was concern about market intelligence. The diversification was felt to be radical, beyond their area of expertise and knowledge base so presenting a steep learning curve. At the extreme, some producers opined they would never contemplate the move because it was fish and not meat. Other producers who had diversification experience of other products (notably horticulture) were keen to simply apply the same model with little regard for the specifics of fish; a potentially high risk strategy given the particular demands of fish compared to other foods. The majority held a more balanced view recognising the need to explore the market for fish, although uncertain of the best means of so doing.

Respondents had very limited awareness of publicly accessible market intelligence concerning fish and critically, exploration of possible grant support for this by some prospective adopters revealed scant availability of assistance either to aid marketing 
intelligence or subsequent knowledge application. This highlighted a significant flaw in policy: the provision of support for new product diversification appears to be encouraged but with no corresponding attempt to encourage or enable prior market assessment. This might be noted as conflicting with good business practice and a potentially significant waste of public money. The apparent reluctance of UK Government agencies to support both production and marketing start-ups of small-scale aquaculture has also proved a problem since such schemes often disallowed support for the type of pilot required to establish the approach in a commercial environment.

Another explanation for the relatively limited interest in adoption might also be the provision of data from the research which typically gave farmers a more detailed and accurate insight into the proposed venture. In most other situations concerning adoption of a new product or process, many more uncertainties would remain at the time of the adoption decision. Possibly more accurate reflections on farmers’ propensity to adopt might have been gained if information had been made more opaque, or less available. For future research one approach to assessing the significance of the quantity and quality of the information provided in advance of the diversification decision may be to reveal different amounts to groups in geographically distant and discrete areas. Notwithstanding the risk of cross communications via other channels, there may be some opportunity, possibly through interim interviews, to gain greater insight to critical levels of information provision at different stages in the decision making process. However this would of course raise not insubstantial ethical issues concerning the welfare impacts upon the adopters.

\section{Conclusions}

Recognition of the benefits and problems generated by aquaculture developments has focussed interest in new species and culture systems that have fewer negative environmental impacts and more social benefits. Organic and traceable fish have been favoured but the 
predominantly carnivorous species raised and the open-cage culture systems used have restricted available options (Aarset et al 2004). Such aquaculture development has largely passed by mainstream UK farming communities and has centred within large-scale commercial interests particularly in coastal Scotland.

This research contributes to understanding of the feasibility of a novel approach to aquaculture, investigating the integration of tilapia into mainstream farming which could generate a supporting income stream to the farm and its local economy. Concomitant positive public health outcomes, at the workplace and community levels might also be expected. The concept could both permit diversification and benefit a different producer group whilst supplying UK niche fresh fish markets. Farm diversification in the UK typically generates very modest income growth (<£6000 net profit annually (UoE, 2002)) and the scale of development is critical to avoid undue risk and encourage participation. The proposed production is based on principles of a variety of normally neutral or positive environmental impacts and ensuring animal welfare considerations. Other potential benefits include reduced carbon footprints; fresher, more accessible and healthier food.

The scale and fuller extent of commercial adoption remains to be seen at present. Whilst the results discussed indicate a generally risk-averse attitude to the adoption of the proposed diversification, a small number of more innovative producers have shown greater interest and more positive signs of adoption. Concerns either about the husbandry and the novel challenges of fish, or the lack of awareness about the market for fish remain common fears. Although there are farmers who have demonstrated some degree of market orientation, through downstream involvement with customers, many still perceive the market for fish to be particularly challenging and difficult. This perception is unlikely to be lessened until a more supportive environment is created especially regarding technical and business support to cover the entire marketing chain. Arguably a more holistic perspective would enable some 
redress of the polarisation of strengths and weaknesses which tend to be found at present, and would help nurture and sustain an environment in which greater emphasis upon ENVF fish product attributes might flourish.

\section{References}

Aarset, B., Bigne,J., Beveridge, M.C., Bjorndal, T., Bunting, M.J.,McDonagh,P., Mariojouls,C., Muir, J.F., Prothero, A., Reisch, L.A., Smith, A.p., Tveteras, R. \& Young, J.A. (2004), The European Consumers' Understanding and Perceptions of the 'Organic' Food Regime: The Case of Aquaculture. British Food Journal. 106(2).

Alder, J.,Campbell, B.,Karpouzi, V., Kaschner, K.,Pauly, D. (2008). Forage fish: from ecosystems to markets. Annual Review of Environment and Resources 33 153-166.

Avnimelech, Y. (1999). Carbon/nitrogen ratio as a control element in aquaculture systems, Aquaculture, 176, 227-235.

Avnimelech, Y, Kochva, M \& Diab, S. (1994) Development of controlled intensive aquaculture systems with a limited water exchange and adjusted carbon to nitrogen ratio.Israel J.Aquaculture Bamidgeh, 46,119-131.

Avnimelech, Y. (2007). Feeding with microbial flocs by tilapia in minimal discharge bioflocs technology ponds. Aquaculture, 264,140-147.

Bell, J.G. and Waagbé, R. (2008), Safe and Nutritious Aquaculture Produce: Benefits and Risks of Alternative Sustainable Aquafeeds. In: Aquaculture in the Ecosystem, M. Holmer, K.D. Black, C.M. Duarte, N. Marba, I. Karakassis, eds. Springer VerlagBV, pp. 185-225.

Beveridge, M., L. Ross, and L. Kelly, (1994) Aquaculture and Biodiversity. Ambio, 23(8): p. 497-502.

Bostock, J., Muir, J.F., Young, J.A., Newton, R. and Paffrath, S. (2008) Prospective Analysis of the Aquaculture Sector in the EU. JRC European Comission and Institute for Prospective Technological Studies. Luxembourg.

Burger, J. and Waishwell, L. (2001), 'Are we reaching the target audience? Evaluation of a fish fact sheet. The Science of the Total Environment. Sep 28;277(1-3):77-86.

Diana, J.S. (2009) Aquaculture production and Biodiversity Conservation. Bioscience 59 (1): 27-38.

FAO. (2009). 'The State of World Fisheries and Aquaculture 2008, Food and Agriculture Organisation of the United Nations http://www.fao.org/docrep/011/i0250e/i0250e00.htm

Fernandez-Polanco, J., Luna, L.and Sanchez, J.L.F. (2008) Consumer determinants for farmed sea bream price acceptance. Proceedings of the European Aquaculture Society Conference: Aquaculture Europe Krakow, Poland. September.

Frewer, L.J. and van Trijp, H. (2007) Looking to the Future Ch 30 (643-649) In L. Frewer and $\mathrm{H}$ van Trijp (Eds) Understanding Consumers of Food Products. Woodhead Publishing Ltd, Cambridge 
Glanz, K. (1999), 'Progress in dietary behavior change.' American Journal for Health Promotion. Nov-Dec;14(2):112-7.

Gofton, L.R. and Marshall, D.W. (1992), Deconstructing sensory preferences; social factors influencing the demand for dark fish. In Pelagic Fish: the resource and its exploitation Eds Burt, J.R., Hardy, R. and Whittle, K.J. pp.272-277. Fishing News Books, Oxford.

Josupeit, H. (2005), World Market of Tilapia, Globefish, FAO, Rome.

Josupeit, H.(2007), Tilapia Market Report, June 2007, Globefish, FAO, Rome.

Kautsky N, Berg H, Folke C, Larsson J, Troell M (1997), Ecological footprint for assessment of resource use and development limitations in shrimp and tilapia aquaculture Aquaculture Research. 28 (10): 753-766.

Kent, R A, (2007) Marketing Research: Approaches, Methods and Applications in Europe, International Thompson Publishing.

Lem, A and Emerson, W. (2008) Globalisation and the dynamics of the International fish trade. Proceedings of the International Institute of Fisheries Economics and Trade 2008 Conference, Nha Trang, Vietnam, July.

Little, D.C., Murray, F.J., Azim, E., Leschen, W., Boyd, K., Watterson, A. and Young, J.A. (2008), Options for producing a warm-water fish in the UK: limits to 'green growth'? et al, Trends in Food Science and Technology 19, 255-264.

MacIntosh, R.P. (2000). Changing paradigms in shrimp farming: IV:low protein feeds and feeding strategies. Global Aquaculture Advocate 2, 40-47.

Naylor, R.L., Goldburg, R.J., Primavera, J.H., Kautsky, N., Beveridge, M.C.M., Clay, J., Folke, C., Lubchenco, J., Mooney, H.\& Troell, M. (2000), Effect of aquaculture on world fish supplies. Nature, 405, 1017-24.

Rayner M and Scarborough P (2005) The Burden of food related ill-health in the UK. Journal of Epidemiology and Community Health.59;1054-1057

Sea Fish Industry Authority, (2008), http://www.seafish.org/upload/file/market_insight/New_Species_0608.pdf 15 July

Serrano, R., Mercedes Barreda, E.P., Hernaandez, F. (2003), Determination of low concentrations of organochlorine pesticides and PCBs in fish feed and fish tissues from aquaculture activities by gas chromatography with tandem mass spectrometry. Journal of Separation Science. 26(12)75-86.

University of Exeter, (2002), Farm diversification in England, 2002. Centre for Rural Research, University of Exeter 20pp. http://www.ex.ac.uk/crr/pdf1/reports1/diverssummary.pdf.

Wasielesky, W., Atwood, H., Stokes, A., Browdy, C. (2006). Effect of natural production in a zero exchange suspended microbial floc based super-intensive culture system for white shrimp Litopenaues vannamei. Aquaculture, 258, 396-403.

Welch RM, and Graham RD (1999), A new paradigm for world agriculture: meeting human needs Productive, sustainable, nutritious. Field Crop Research.60 (1-2): 1-10. 
Wessells, C.R.and Anderson, J.G. (1995) Consumer willingness to pay for seafood safety assurances Journal of Consumer Affairs 29, 85-107.

Wong, E.Y., Ponce, R.A., Farrow, S., Bartell, S.M., Lee, R.C. and Faustman E.M. (2003), Comparative risk and policy analysis in environmental health. Risk Analysis. Dec;23(6):1337-49.

Young, J. A., C. Brugere, and J. Muir. (1999), Green Grow The Fishes-Oh? Environmental Attributes in Marketing Aquaculture Products, Aquaculture Economics \& Management, 3(1): 7-17.

Young, J.A., Grady, K., Little, D.C; Watterston, A., and Murray, F. (2006), Multidisciplinary Perspectives on an Emergent Fish Product: the tank of British tilapia, Proceedings of the International Institute of Fisheries Economics and Trade 2006 Conference, University of Portsmouth, July. 